\title{
Is it Possible to Diagnose Endometrium Cancer with the Levels of Prolactin, Eotaxin, E-selectin and Ca 125?
}

\author{
(10 Özgüç TAKMAZ11, id Sinan BERKMAN²
}

'Acıbadem Mehmet Ali Aydınlar University, Clinic of Gynecology and Obstetrics, İstanbul, Turkey

2Florence Nightingale Hospital, Clinic of Gynecology and Obstetrics, İstanbul, Turkey

\section{ABSTRACT}

Objective: The aim of this study to evaluate possible serum markers for distinction of endometrial carcinoma (EC) from benign uterine gynecologic diseases.

Methods: The study group consisted of 65 patients who were diagnosed with histologically confirmed EC were compared with 65 women who had operation indication for benign uterine diseases with fasting blood serum levels which were taken prior to surgery in terms of prolactin, eotaxin, e-selectin and Ca 125 concentrations.

Results: Serum prolactin (20.7 \pm 18 and 16.2 \pm 13$)$, eotaxin (219.4 \pm 95 and $205.15 \pm 80)$ and e-selectin $(67.2 \pm 29$ and $61.5 \pm 29)$ levels were not

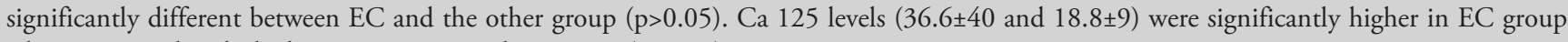
when compared with the benign uterine patology group $(\mathrm{p}<0.05)$.

Conclusion: Although serum levels of prolactin, eotaxin, e-selectin were higher in EC group, those were not statistically significant. Although, serum Ca 125 levels were siginificantly higher in EC group, diagnostic role of $\mathrm{Ca} 125$ is limited. There is currently no marker to distinguish EC from benign uterine pathologies.

Keywords: Prolactin, eotaxin, E-selectine, Ca 125, endometrial cancer marker

\section{Introduction}

Endometrium cancer (EC) is the most common gynecologic cancer in developed countries (1). The survival rates of EC are much higher as in many other cancers in case of early diagnosis and given appropriate surgical and medical treatment (2). The diagnosis of $\mathrm{EC}$ is most commonly made as a result of endometrial sampling in the patient suffering from bleeding in menopause or irregular bleeding. Although endometrial sampling is a procedure made from natural holes in the body, it is an invasive procedure and its cost is significantly higher when compared with a simple blood test. It also has a complication risk.
Mortality risk of EC increases due to histological grade of tumor, lympho-vascular area invasion, tumor size, cervical involvement and metastasis to lymph nodes (3). The importance of tumor markers and some cytokines, chemokines, adhesion molecules and growth factors have been studied many times in cancer diseases. The development of tumor cells has been shown to increase with the effect of cytokines [interleukin (IL)-4, 6, 10), chemokines (IL)-8, eotaxin], growth factors, adhesion molecules (selectins, integrins) and enzymes such as nitric oxide synthetase and cyclooxygenase-2 (4). Although immune cells have tumor suppressor effects in early stage cancers, they are able to increase tumor spread and metastasis due to some phenotypic modifications

Address for Correspondence: Özgüç TAKMAZ, Acıbadem Mehmet Ali Aydınlar University, Clinic of Gynecology and Obstetrics, i̇stanbul, Turkey

E-mail: ozguctakmaz@hotmail.com ORCID ID: orcid.org/0000-0002-3397-7980

Cite this article as: Takmaz Ö, Berkman S. Is it Possible to Diagnose Endometrium Cancer with the Levels of Prolactin, Eotaxin, E-selectin and Ca 125?. Bezmialem Science 2019;7(4):281-5. 
in advanced stages (5). Chemokines are proteins also involved in the cancer process that regulate the distribution and traffic of immune cells. There are studies showing the stimulating effects of chemokines in some human cancers (6). Furthermore, increased chemokine receptor expression has been reported to be associated with poor prognosis and metastasis (7). Eotaxin-1 is a chemokine that has been discovered as an eosinophile selective chemoattractant. Eotaxin mRNA expression has been shown in many tissues, including the endometrium (8). The direct angiogenic effect of eotaxin has been shown to explain its role in metastasis and tumor invasion (9).

L-selectin (CD62L), E-selectin (CD62E), P-selectin, and integrins are molecules likely to be effective in the progression of tumor cells. Endothelial E-selectin is involved in wound healing and infections by providing leukocyte participation along with P-selectin. However, this role of selectins can have unintended consequences in pathological situations such as chronic inflammation and cancer (10). Many studies have shown increased carcinogenetic potency in prolonged inflammatory diseases such as chronic pancreatitis, inflammatory bowel disease and prostatitis (11). Increased selectin and selectin receptors have been identified in many tumor cells. This causes selectin to interact with tumor cells, attracting these cells to systemic circulation and metastasis (12).

Tumor markers are substances in the form of hormone, enzyme, metabolite, immunoglobulin, or protein which are produced by tumor or tissue in supraphysiological levels and their quantitative measurements can be done in patient's tissue, blood or other body fluids with biochemical or immunochemical methods. They may also include tumor-related antigens, oncogene, and oncogene products. An ideal tumor marker should have high sensitivity and specificity, allowing recognition and curative treatment of the tumor while the tumor is still small or the patient is asymptomatic.

Tumor markers are used to recognize tumors as early as possible, improving clinical outcomes and survival. Ca 125 is a tumor marker used in diagnosis and follow-up of ovarian cancer, and it is known that levels of $\mathrm{Ca} 125$ are elevated in advanced stage EC (13). Ca 125 is a marker belonging to the mucin family of glycoproteins and located on the surface of mesothelial cells, which can be elevated in many benign conditions (endometriosis, tuboovarian abscess) other than ovarian and EC (14). Therefore, it has limited sensitivity and specificity in the diagnosis of ovarian and EC (15).

Prolactin is a protein molecule that acts as a hormone and cytokine that enables the production of milk secreted from the pituitary gland. The anti-apoptotic or mitogenic efficacy of prolactin in breast and glial cells is known (16). There are studies showing that prolactin may be effective in prostate cancer, lymphoma and leukemia, besides breast cancer (17-19). Prolactin is also synthesized in the endometrium, myometrium and cervix. There is only one study in the literature showing that prolactin increases in EC (20). There are also a limited number of studies in which prolactin levels are evaluated in cervical and other gynecologic cancers, but no clear association between prolactin levels and cancer has been shown in these studies (21).

Although EC is the most common gynecological malignancy, it is not ideal to screen the entire population due to the lack of an ideal method to sample the endometrium under examination conditions and the lack of a specific blood test of EC. Especially, postmenopausal women using oral contraceptives containing estrogen only, women with Lynch syndrome [hereditary nonpolyposis colorectal cancer (HNPCC)] and with chronic anovulatory cycles due to polycystic ovary syndrome can be taken in screening programme.

In this study, we compared serum prolactin, e-selectin, eotaxin and Ca 125 levels between patients with benign gynecologic pathologies and patients with EC diagnosis and evaluated the possibility of using these cytokines in diagnosis of $\mathrm{EC}$ without intervention.

\section{Methods}

This study was conducted in the XX institution with the approval of the Ethics Committee of the institution (protocol number 2009/1920) as a prospective single-center study. Informed consent forms were obtained from all patients included in the study. All procedures were carried out in accordance with the Helsinki Declaration.

The study group was composed of 65 patients who were histologically diagnosed as having EC, while the control group was composed of 65 patients who did not have gynecological and non-gynecological malignancies and who were operated for benign reasons such as myoma and uterine prolapse. The additional diagnosis was made by the evaluation of tissue samples taken by the endometrial curettage method, by gynecopathologists and this diagnosis was confirmed by hysterectomy materials examined after the operation. It was confirmed after the operation that the pathology results of the patients operated due to benign pathologies were also benign.

Five millilitres of fasting blood samples were taken from both groups on the morning of the surgery. On the same day, prolactin, Ca 125, Ca 19-9 and Ca 15-3 concentrations were measured in the E170 modular system (Roche Diagnostics, Mannheim, Germany) by electrocemoiliminusance method.

For measurement of serum eotaxin and E-selectin levels, blood samples taken in gel tube were centrifuged at $4000 \mathrm{rpm}$ and the upper phases were separated and samples were stored at $-80^{\circ} \mathrm{C}$ until the study day and E-selectin concentrations (eBioscience, Vienna, Austria) and eotaxin levels (Invitrogen, California, USA) were measured using commercial kits using the sandwich enzyme immunoassay method.

\section{Statistical Analysis}

For statistical analysis, SPSS 15.0 (SPSS Inc. Chicago, IL., USA) package program was used. The distribution of variables between groups was presented with average and standard deviation values. The compatibility of variables with normal distribution was 
evaluated by Kolmogorov-Smirnov test. The Mann-Whitney U test was used to evaluate the difference between the two group averages. Statistical significance level was selected as $\mathrm{p}<0.05$.

\section{Results}

The mean age of the EC group was $56.8 \pm 12$ and the mean age of the benign uterine pathology group was $54.6 \pm 9$ years. There were no statistically significant differences between the groups in terms of age $(p>0.05)$.

There were no statistically significant differences between groups in terms of prolactin level $(20.7 \pm 18 \mathrm{ng} / \mathrm{mL}$ vs $16.2 \pm 13 \mathrm{ng} /$ $\mathrm{mL})$, eotaxin level $(219.4 \pm 95 \mathrm{pg} / \mathrm{mL}$ vs $205.1 \pm 80 \mathrm{pg} / \mathrm{mL})$ and E-selectin level $(67.2 \pm 29 \mathrm{ng} / \mathrm{mL}$ vs $61.5 \pm 29 \mathrm{ng} / \mathrm{mL})(\mathrm{p}>0.05)$.

However, there was significant difference between the EC group and the benign uterine pathology group in terms of $\mathrm{Ca} 125$ levels $(36.6 \pm 40 \mathrm{u} / \mathrm{mL}$ vs $18.8 \pm 9 \mathrm{u} / \mathrm{mL})(p<0.05)$ (Table 1).

\section{Discussion}

Preoperative tumor marker analysis is important not only for diagnosing the tumor but also for therapeutic follow-up. With effective new biomarkers, the clinician will be able to diagnose early and evaluate treatment effectiveness. In our study, we evaluated markers that could distinguish EC from benign uterine pathologies. In our study, we found that prolactin, eotaxine, E-selectin and Ca 125 levels were higher in the serum of patients with EC than in the serum of patients with benign uterine pathologies, but only increase in Ca 125 was statistically significant. The elevations in prolactin, eotaxine and E-selectin levels were not statistically significant.

It is known that prolactin is not just a hormone secreted from the pituitary gland, it has paracrine and autocrine activity in many tissues and prolactin is produced in the secretory phase in the endometrium (16). Although the role of prolactin in carcinogenesis is not known, studies have shown that it increases in breast and prostate cancer $(19,22)$. There are a limited number of studies showing increased levels of prolactin in EC in the literature. Yurkovetsky et al. (20) evaluated patients with EC with a comprehensive serum marker panel in their study. As a result of that study, prolactin was found to be $98 \%$ specific and 98\% sensitive in the diagnosis of EC (20). Kanat-Pekkaş et al. (21) also showed that prolactin levels were significantly higher in patients with EC, but it was indicated that the use of prolactin alone was a remote possibility for screening or as a marker. In our study, prolactin was found to be high in patients with EC compared to patients with benign uterine pathologies, but this difference was not statistically significant.

Blockade of eotaxine signaling pathway increases chemotherapeutic efficacy which supports the effectiveness of this chemokine in cancer growth and metastasis (23). Nolen et al. (24) showed that eotaxin decreased in ovarian cancer and it was also reported that eotaxin decreased in patients with EC in the panel which was evaluated in the study by Yurkovetsky et al. (20). In our study, eotaxin levels were higher in patients with EC than in patients with benign uterine pathologies. However, this difference did not reach a statistically significant level.

In our study, we found no significant difference in E-selectin level. There are publications in the literature showing the relationship between increase in E-selectin level in breast and colon cancer and metastatic disease (25). The only study in which E-selectin was evaluated in EC was the study of Yurkovetsky et al. (20), in which E-selectin was found to decrease significantly in EC. Furthermore, even if significant changes in the level of E-selectin are detected, this cytokine may increase in many chronic diseases, which reduces the likelihood of being used as a cancer marker (26).

In our study, Ca 125 was the only marker we found significantly higher in the serum of patients with EC. This marker produced by coelomic epithelium may increase in other gynecologic malignancies, especially ovarian tumors, and in some benign conditions (endometriosis, pelvic infection, pregnancy, myoma) $(27,28)$. It was found to increase in $11-33 \%$ of patients with EC (29). Although increase in Ca 125 in EC is generally associated with extra-uterine propagation, many studies have shown that it correlates with stage, deep myometrial invasion, positive peritoneal cytology, and lymph node metastasis (30). It is also known to be a marker of disease activation in the follow-up process after treatment. Serum Ca 125 levels above $70 \mathrm{U} / \mathrm{mL}$ was claimed to be associated with prognosis in the multicenter study in 413 patients with EC by Kim et al. (30). In our study, the mean Ca 125 level was 36.6 in the EC group. Given the finding in our study and literature, it should be underlined that Ca 125 may be important for follow-up in EC, but its use area is limited due to its low specificity as a screening parameter.

The most important limitation of our study was that our patient numbers were partially low. Evaluations in a larger study group will contribute greatly to the use of these parameters in EC.

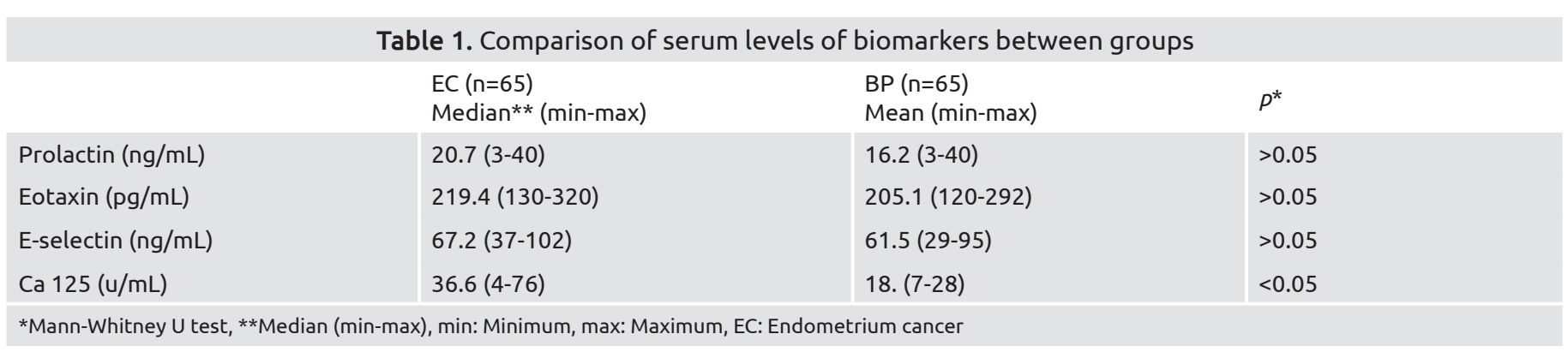




\section{Conclusion}

Prolactin, eotaxine and E-selectin levels are not different between patients with EC and patients with benign uterine disease. It is not possible to use these hormones and cytokines as serum markers and to use them for screening and diagnosis in EC. Although Ca 125 has been found high in patients with EC, it is still not qualified for screening or diagnosis due to low specificity. This issue with contradictory results in the literature seems likely to be clarified when re-evaluated with studies with higher number of cases.

\section{Ethics}

Ethics Committee Approval: This study was conducted prospectively in the Department of Obstetrics and Gynecology of Istanbul Medical School with the approval of the ethics committee (protocol number 2009/1920).

Informed Consent: Informed consent forms were obtained from all patients included in the study.

Peer-review: Externally peer-reviewed.

\section{Authorship Contributions}

Concept: S.B., Design: Ö.T., Data Collection or Processing: S.B., Analysis or Interpretation: S.B., Literature Search: Ö.T., Writing: Ö.T.

Conflict of Interest: No conflict of interest was declared by the authors.

Financial Disclosure: The authors declared that this study received no financial support.

\section{References}

1. Engelen MJ, Kos HE, Willemse PH, Aalders JG, de Vries EG, Schaapveld M, et al. Surgery by consultant gynecologic oncologists improves survival in patients with ovarian carcinoma. Cancer 2006;106:589-98.

2. Mercado C, Zingmond D, Karlan BY, Sekaris E, Gross J, MaggardGibbons M, et al. Quality of care in advanced ovarian cancer: the importance of provider specialty. Gynecol Oncol 2010;117:18-22.

3. Siegel RL, Miller KD, Jemal A. Cancer statistics, 2018. CA Cancer J Clin 2018;68:7-30.

4. Smith HA, Kang Y. The metastasis-promoting roles of tumorassociated immune cells. J Mol Med (Berl) 2013;91:411-29.

5. Ostrand-Rosenberg S. Immune surveillance: a balance between protumor and antitumor immunity. Curr Opin Genet Dev 2008;18:11-8.

6. Meijer J, Zeelenberg IS, Sipos B, Roos E. The CXCR5 chemokine receptor is expressed by carcinoma cells and promotes growth of colon carcinoma in the liver. Cancer Res 2006;66:9576-82.

7. Schimanski CC, Schwald S, Simiantonaki N, Jayasinghe C, Gonner U, Wilsberg V, et al. Effect of chemokine receptors CXCR4 and CCR7 on the metastatic behavior of human colorectal cancer. Clin Cancer Res 2005;11:1743-50.
8. Zhang J, Lathbury LJ, Salamonsen LA. Expression of the chemokine eotaxin and its receptor, CCR3, in human endometrium. Biol Reprod 2000;62:404-11.

9. Salcedo R, Young HA, Ponce ML, Ward JM, Kleinman HK, Murphy WJ, et al. Eotaxin (CCL11) induces in vivo angiogenic responses by human CCR3+ endothelial cells. J Immunol 2001;166:7571-8.

10. Ludwig RJ, Schon MP, Boehncke WH. P-selectin: a common therapeutic target for cardiovascular disorders, inflammation and tumour metastasis. Expert Opin Ther Targets 2007;11:1103-17.

11. Bock D, Philipp S, Wolff G. Therapeutic potential of selectin antagonists in psoriasis. Expert Opin Investig Drugs 2006;15:96379.

12. Witz IP. Tumor-microenvironment interactions: the selectin-selectin ligand axis in tumor-endothelium cross talk. Cancer Treat Res 2006; 130:125-40.

13. Chung HH, Kim JW, Park NH, Song YS, Kang SB, Lee HP. Use of preoperative serum CA-125 levels for prediction of lymph node metastasis and prognosis in endometrial cancer. Acta Obstet Gynecol Scand 2006;85:1501-5.

14. Miralles C, Orea M, Espana P, Provencio M, Sanchez A, Cantos $\mathrm{B}$, et al. Cancer antigen 125 associated with multiple benign and malignant pathologies. Ann Surg Oncol 2003;10:150-4.

15. Buamah P. Benign conditions associated with raised serum CA-125 concentration. J Surg Oncol 2000;75:264-5.

16. Ben-Jonathan N, Mershon JL, Allen DL, Steinmetz RW. Extrapituitary prolactin: distribution, regulation, functions, and clinical aspects. Endocr Rev 1996;17:639-69.

17. Nevalainen MT, Valve EM, Ingleton PM, Nurmi M, Martikainen PM, Harkonen PL. Prolactin and prolactin receptors are expressed and functioning in human prostate. J Clin Invest 1997;99:618-27.

18. Kooijman R, Gerlo S, Coppens A, Hooghe-Peters EL. Myeloid leukemic cells express and secrete bioactive pituitary-sized $23 \mathrm{kDa}$ prolactin. J Neuroimmunol 2000;110:252-8.

19. Llovera M, Pichard C, Bernichtein S, Jeay S, Touraine P, Kelly PA, et al. Human prolactin (hPRL) antagonists inhibit hPRL-activated signaling pathways involved in breast cancer cell proliferation. Oncogene 2000;19:4695-705.

20. Yurkovetsky Z, Ta'asan S, Skates S, Rand A, Lomakin A, Linkov F, et al. Development of multimarker panel for early detection of endometrial cancer. High diagnostic power of prolactin. Gynecol Oncol 2007;107:58-65.

21. Kanat-Pektas M, Yenicesu O, Gungor T, Bilge U. Predictive power of sexual hormones and tumor markers in endometrial cancer. Arch Gynecol Obstet 2010;281:709-15.

22. Ben-Jonathan N, Liby K, McFarland M, Zinger M. Prolactin as an autocrine/paracrine growth factor in human cancer. Trends Endocrinol Metab 2002;13:245-50.

23. Lorena SC, Oliveira DT, Dorta RG, Landman G, Kowalski LP. Eotaxin expression in oral squamous cell carcinomas with and without tumour associated tissue eosinophilia. Oral Dis 2003;9:279-83.

24. Nolen BM, Lokshin AE. Targeting CCL11 in the treatment of ovarian cancer. Expert Opin Ther Targets 2010;14:157-67. 
25. Tesarova P, Kvasnicka J, Umlaufova A, Homolkova J, Kalousova M, Tesar V. Soluble adhesion molecules in female patients with breast carcinoma. Cas Lek Cesk 2003;142:292-9.

26. Roldan V, Marin F, Lip GY, Blann AD. Soluble E-selectin in cardiovascular disease and its risk factors. A review of the literature. Thromb Haemost 2003;90:1007-20.

27. Takanami I. Overexpression of CCR7 mRNA in nonsmall cell lung cancer: correlation with lymph node metastasis. Int J Cancer 2003;105:186-9.
28. Rustin GJ, Bast RC, Jr., Kelloff GJ, Barrett JC, Carter SK, Nisen PD, et al. Use of CA-125 in clinical trial evaluation of new therapeutic drugs for ovarian cancer. Clin Cancer Res 2004;10:3919-26.

29. Scambia G, Gadducci A, Panici PB, Foti E, Ferdeghini M, Ferrandina G, et al. Combined use of CA 125 and CA 15-3 in patients with endometrial carcinoma. Gynecol Oncol 1994;54:292-7.

30. Kim HS, Park CY, Lee JM, Lee JK, Cho CH, Kim SM, et al. Evaluation of serum CA-125 levels for preoperative counseling in endometrioid endometrial cancer: a multi-center study. Gynecol Oncol 2010;118:283-8. 